
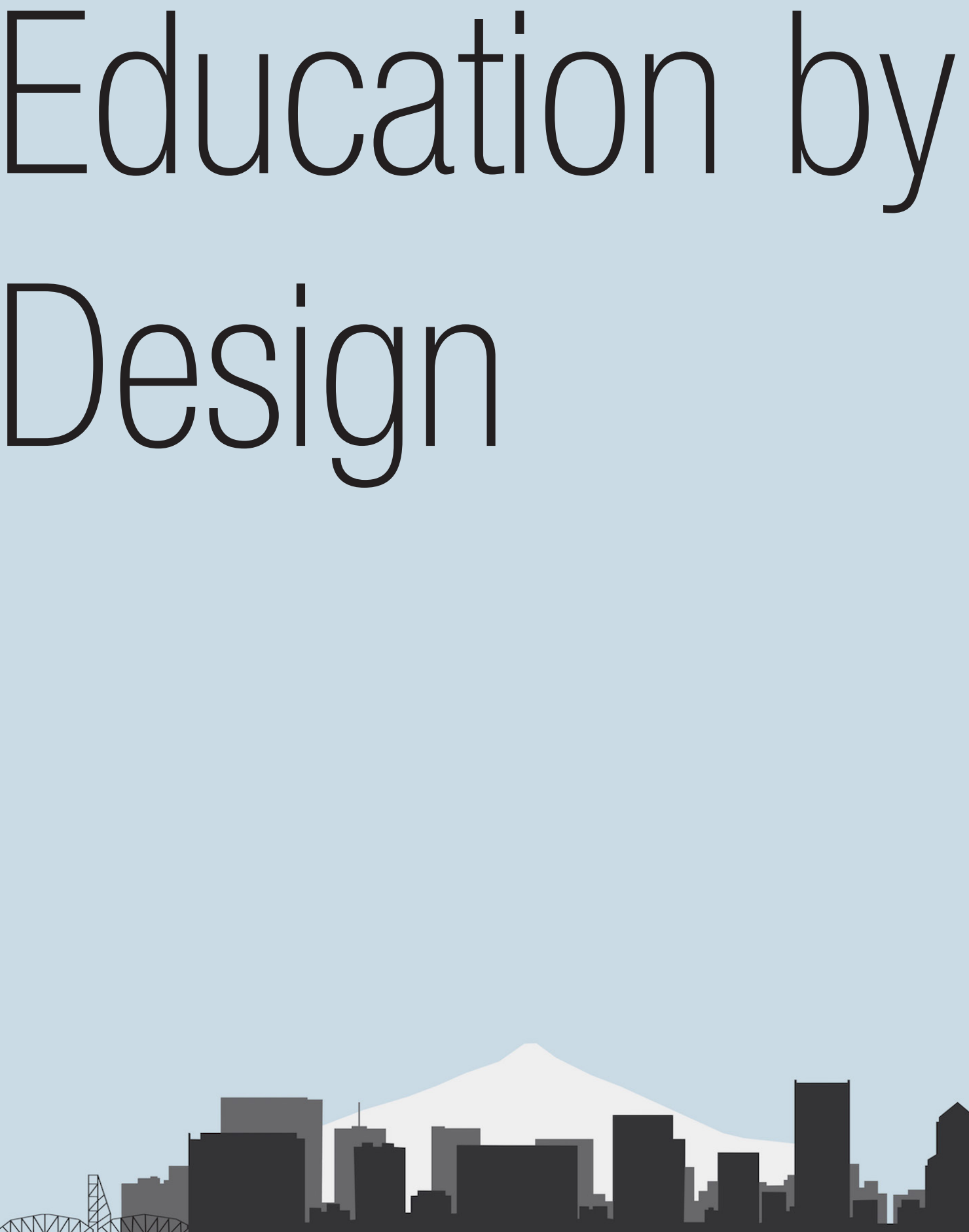

2019 Reynolds Symposium: Education by Design October 18-20, 2019 


\section{Organizing Committee:}

[co-organizers]

Professor Alison Kwok, Ph.D, FAIA, University of Oregon

Emeritus Professor John Reynolds, FAIA, University of Oregon

\section{[Symposium coordinator]}

Isabel Rivera, Ph.D., University of Oregon

Professor Walter Grondzik, P.E., Ball State University

Professor Bruce Haglund, AIA Assoc., University of Idaho

Assistant Professor Emily McGlohn, AIA, Auburn University

Associate Professor Ulrike Passe, lowa State University

Assistant Professor Siobhan Rockcastle, Ph.D., University of Oregon

Sharon Refvem, FAIA, LEED Fellow, Senior Associate and Director, Sustainability Resource Group, Hawley Peterson Snyder 


\title{
Making Site Matter: Expanding the Field of Architectural Technology
}

\author{
Robert Arens, AIA \\ Professor \\ California Polytechnic State \\ University \\ San Luis Obispo, California \\ rarens@calpoly.edu
}

\author{
Brian Osborn, PLA \\ Assistant Professor \\ California Polytechnic State \\ University \\ San Luis Obispo, California \\ bosboro1@calpoly.edu
}

\author{
Carmen Trudell, RA \\ Associate Professor \\ California Polytechnic State \\ University \\ San Luis Obispo, California \\ ctrudell@calpoly.edu
}

\begin{abstract}
Globalization and the spread of modernism have led to what critics have described as a standardization of the built environment. As architects have turned their attention back to site in recent decades a significant discourse surrounding its potential as a generative concern in the production of architecture has emerged.

Despite this recovery, the integration of site into architectural practice remains a work in progress. The stalled progress is no doubt related to a tentative engagement with site in architectural education.

Through an assessment of our curriculum at Cal Poly we have found that by not addressing it explicitly in our coursework, we leave site outside the domain of architecture and excluded from meaningful design authorship.

In an effort to construct a broad framework for site matters within our curriculum, we have discovered potential in incorporating site into Architectural Technology Fundamentals courses. To do so we have reorganized these courses into three study areas: Site and Contextual Systems, Materials and Construction Systems, and Energy and Environmental Systems. Since site is in constant dialogue with each of these within the built environment, we find value in presenting it to students in the same interconnected way. This paper discusses our rationale and methods for incorporating site into architectural technology courses.
\end{abstract}

\section{INTRODUCTION}

Until three years ago, the Architecture Program at Cal Poly San Luis Obispo addressed site primarily through studio projects. In our minds, design instructors regularly encouraged students to engage a site's physical, material and legal conditions as part of the design process, and perhaps went further to explore site beyond physical delimitations and consider its cultural, conceptual and ecological potential.

Of course, this wasn't always the case as site was sometimes addressed in a cursory manner or excluded from meaningful authorship by designers altogether. By indirectly addressing site through the design studio, we had encouraged an inconsistent and or incomplete understanding of the multilayered aspects of site and its role in design thinking. To address this, we set out to bring the study of site directly and explicitly into our curriculum. This raised important questions about how to integrate site, where in the curriculum to integrate it, and most importantly why to integrate it.

Although there were few options for integrating site into already-existing courses, we saw opportunities in integrating site into our sequence Architectural Technology Fundamentals courses. Our reading of site as a series of systems (climatic, material, hydrological, legal, social, etc.), encouraged us to seek ways to connect site systems to those traditionally discussed within architectural technology, such as materials, methods of construction, and environmental control systems. Perhaps most importantly, we challenged ourselves innovate and to use site to rethink technology and vice versa, and to ask what if the lines between site and object and between nature and technology could find more synthetic convergence? 


\section{SITE: ABSTRACT, PHYSICAL, AND EXPERIENTIAL HISTORIES}

Site is an inevitable condition of buildings: to construct a building means to locate it somewhere. That said, the role of site in the formulation of architecture elicits a complex set of concerns about what aspects are engaged and to what extent. The potency of these concerns is largely the result of the multiple and layered interpretations that are available when considering sites. These include both abstract and physical, as well as experiential implications, which can exist simultaneously and often in conflict with each other.

The legal definition of site describes an area determined by the often-mathematical division of land. The product of which allocates the site a numeric address and places it under the ownership of someone or some entity and within the jurisdiction of a local political authority. Along with ownership comes the potential for a site to fulfill a desired programmatic function; agriculture, housing, industry, recreation, etc. Along with jurisdiction comes a set of regulatory expectations, such as zoning codes, that establish allowable uses and outline a potential building envelope through setback requirements, floor-area-ratios, lot coverage limitations, and building height and bulk maximums. These conditions of site are abstract, in that they are not intrinsic to the site itself but are instead applied as a result of external motivations; efficiency, economic, political, or otherwise. Nonetheless, these conditions allow for a very real shaping of physical building form and, especially in urban contexts, the creation of a public realm beyond the building.

Sites are also the product of a physical and material history. This includes what Carol Burns describes as natural constructors such as climate, solar geometry, hydrology, geology, landform morphology, and biology. Related are influences from human transformations on the land such as settlement patterns, transportation infrastructures, and agricultural and industrial systems (1991). These conditions engender a perceived sensitivity for physical landscape processes and suggest that building form develop in response to them.

Finally, sites also project a more immediate experiential sensation "...such as the effect of early morning light on undulating surfaces [,] or consideration for the emergence of a wildflower color-field that quickly disappears into the background of a meadow (Meyer 2005, 110-111)." This more subjective interpretation engages site's temporal qualities and results from the episodic interaction of sun, wind, and climate with specific material configurations. Elizabeth Meyer describes these moments as haeceities-individual, singular events that intersect with the places and things where they occur (2005). Similarly, an experiential interpretation of site may also include the physical suitability of its various spaces for accommodating program, and or the cultural association between typological spaces and patterns of use. For example, the valley floor is a landscape type that has long been associated with public space and activity while the ridge, or promontory, is a typology more often associated with the dwelling of gods and the enlightened (Heymann 2010b). William Moorish explores these associations beautifully in Civilizing Terrains: Mountains, Mounds, and Mesas.

\section{SITE VERSUS TECHNOLOGY}

These histories have not always been understood to be relevant to the formulation of architecture. This relevance was especially low within the late 19th and early 20th centuries during the rapid development of industry and the subsequent translation of modernist ideals to architecture. In fact, the development of a meaningful discourse of site can be understood to be directly at odds with the increasing value placed on technical expertise in building construction and systems.

As William Braham describes, the shift from an agrarian to an industrialized economy that occurred in the United States after the Civil War, and which coincided with the beginnings of the modernist movement, radically altered the role of technological knowledge in architecture (2012). Prior to this, design and engineering had been understood to be distinct areas of interest and architectural education could be categorized by one of two schools-the École des Beaux-Arts, grounded in the arts and humanities, or the École Polytechnique, which is based in the methodologies of science and engineering. The inclusion and continual integration of technological knowledge with design, Braham argues, is the result of a discipline 
attempting to remain relevant in "an industrializing economy-involving new patterns of settlement and modes of transportation, new places of work, new forms of communication, and new means and methods of construction $(2012,392)$." A resolution passed at the 47th Annual Meeting of the Associated Collegiate Schools of Architecture (ACSA) in 1961 memorializes this shift in values:

"On integration of Design and Structures:

A resolution has been adopted: That so-called construction and so-called design are inseparable parts of a single unit known as Architectural Design, and so far as it is possible the teaching of these two branches should be considered inseparable and coordinated and correlated in the Schools.

-Prof Laird-1920 (1961)"

At the same time, this preoccupation with technology resulted in a disinterest in site specificity. "Motivated by technological developments, the possibility of producing widely available quality goods, and a social program with utopian aspirations, the modernist program in conjunction with a developing global economy led to standardization of environments and cultures (Burns 1991, 148).” The so-called man-made technological environment produced a homogenous architecture that is impartial to the specific circumstances of site and program (Moholy-Nagy 1955).

Over the last 50 years, however, and largely in reaction to the widespread homogeneity of architectural form, the role of site in the formulation of architecture has evolved through the writing and practice of several architects. "As the awareness of the relationship between cultural production and the local circumstances of material practice has come to the fore, attention to site has begun to frame the problem of making and interpreting architecture (Burns 1991).”

David Heymann summarizes the site's evolving role during this period as a shift from approaching site as merely a setting to engaging it as a source of experience. Within this distinction, works that take the site as a setting are "fundamentally about the internal concerns of [the architect], and [have] little to do with the qualities of a specific place (Heymann 2010b, 1)." Alternatively, works that position the site as a source are "entirely the by-product of certain circumstances true to the site (Heymann 2010b, 1)." To place the site as a source into the three histories outlined above, Heymann's truths tend to reflect those physical and experiential conditions that can be found within the site itself or in the larger geo-physical systems that influence its formation.

\section{STEPS TO AN INTEGRATION OF SITE}

Despite a significant recovery of site as a generative concern in the production of architecture, the integration of site's complex histories into architectural discourse remains a work in progress. Three observations can be drawn out of the existing discourse as a guide for future work: that productive readings of sites can come from a negotiation of their multiple and conflicting histories; that sites are inherently unfinished-in a state of constant iteration in which architecture plays a critical role; and that that process of site making exists within the domain of architecture, and architects.

In her essay “On Site: Architectural Preoccupations”, Carol Burns discusses two common conceptions of site within architecture: the cleared site and the constructed site. Each suffers from a redaction of the other. "The cleared site is based on the assumption that the site as received is unoccupied, lacking any prior constructions and empty of content (Burns 1991, 149).” The logic of the cleared site is governed only by the abstracted geometry of subdividing land into lots, while natural constructors and human transformations are ignored. The constructed site, alternatively, “...emphasizes the visible physicality, morphological qualities, and existing conditions of land and architecture (Burns 1991, 153).” The constructed site conception can be understood as respectful to the landscape and immediate context yet ignores implications of previous ownership, cultural associations, haecceities, and other invisible or ephemeral conditions. Burns' comparison points out that any history taken in isolation enables only a partial engagement with site.

Alternatively, placing a site's multiple histories in dialogue with each other allows architecture to result from their negotiation. Through this negotiation architects exert critical thinking, intention, and 
authorship in the development of site strategies. David Heymann's analysis of the Tarlo House, designed by Tod Williams Associates in 1978, provides a useful starting point for examining the potential of negotiated site histories. Heymann argues that despite occupying what could easily be understood as unexceptional land; resulting from the abstract subdivision of a former potato field, “...the Tarlo House is construed of formal gestures that are almost without exception site responses, rather than functional tactics (Heymann 2010b).” This critique makes sense, given Heymann's interest in establishing that a shift from site as setting to site as source has taken place over the latter half of the 2oth Century. Compared, by Heymann, to Case Study House \#4, by Ralph Rapson, designed in the 1940's for a similarly cleared site condition, The Tarlo House utilizes the site as a source of solar geometry and prevailing winds in order to generate the experience of the house. Alternatively, Case Study House \# 4 avoids a physical history and inherits instead the abstract logic that delineated the site's boundaries as a truth on which to base form. Given the lack of engagement with any condition intrinsic to the site, Case Study House \#4 represents, in Heymann's terms, an example of a site being use merely as setting. However, it could also be argued that the form of the Tarlo House results from the relationship between a response to the mathematical condition of the site's abstract setting, on one hand, and the tuning of the house to the site's larger geo-physical sources on the other. As Heymann describes, the Tarlo House is made up of 4 formal elements: a screen wall along the north edge of the site provides privacy, a brise-soleil along the south edge that shades the house from summer sun, the main volume of the house provides the interior program, and a suspended deck that connects the main volume to the northern wall. While the main volume of the house is rotated in order to orient its long dimension to the south and maximize solar gain during the winter months, the screen wall and the brise-soleil are geometric offsets of the property boundary. The misalignment between the two screening elements at the site perimeter and the rotated volume lead to the ragged southern edge of the interior, which divides the otherwise open ground floor plan into a sequence of three spaces. In addition, a series of outdoor spaces are articulated between the volume and its delaminated façade. Like the interior space, these exterior rooms also benefit from the shading and privacy produced by the outer walls. While the Tarlo House does respond directly to the climatic and solar conditions of its site, its nuanced form and spatial configuration is better characterized as a negotiation between layered site histories.

A second observation follows from the notion that sites exist in a state of constant iteration. We have chosen here to describe the various conditions that contribute to a sense of site as histories in order to promote a sense that each is the result of a continuous and chronological sequence and will give way to an equally iterative future. Carol Burns laments, "...site is frequently seen as a synchronic phenomenon, irrevocably divorced from other times $(1991,149)$." Of course, to understand a site as a result of the physical and material forces acting upon it, as is the case in Burns' constructed site and in Heymann's site as source, assumes the dynamics of change-over-time that must have been behind the form of the site. However, Burns suggests that this procedural understanding of site tends to stop at the present visible form. Convincingly, she argues that "the exclusive object of site planning is space; the potential to plan or "plot" time is not pursued (1991, 149)."

The implication of a temporal and non-hierarchical conception of site is the potential value given to it from human and natural interactions. As a site is made as much as it is received, the process of making architecture must also be the process of making site. As Burns points out, "adding a new building to a site transforms its use as well as its topography, microclimate, and circulation $(1991,164)$." This is likely the realization that led her to insist that site must be construed as well as constructed. A responsible approach therefore is to engage the role of architecture in the making of site toward intentional and informed interactions between the two. Doing so requires that site be considered within the domain of architecture such that the means and methods of constructing it are an integral part the architect's vocabulary and knowledge set.

\section{SITE IN ARCHITECTURAL EDUCATION}

The stalled integration of site into the discourse of architecture is no doubt related to a tentative engagement with site in architectural education. In an effort to understand how site is introduced within schools of architecture we reviewed a variety of curricula, as they can be understood through their programs' websites. As a way to get started we focused on programs that appear in Design Intelligence's 
list of the Most Admired Architecture Schools. It should also be noted that we do not wish to imply that these rankings, on their own, give validity to the curriculum of a school. They do provide a sampling of schools situated in both private and public institutions, as well as those from both École des Beaux-Arts and École Polytechnique traditions. A more exhaustive survey, which we plan to execute in the future, would look beyond course catalog descriptions and examine the circumstances in which any particular approach to site was born.

Our initial survey concluded that schools tend to address site in 1 of 5 ways: 1) through stand-alone courses such as "Site Design" or "Site Analysis and Planning"; 2) through an introduction to topics related to the natural environment, such as "Environmental Systems" or "Sustainability"; 3) through courses that explore a specific contextual typology, such as "Urban", or a specific city, such as "New York", "Chicago", "Houston", "Paris", or "Rome"; 4) through a required introductory course to an affiliate discipline, such "Landscape Architecture" or "Urban Design"; and 5) through design studio topics.

Aside from those programs that introduce site explicitly in courses on "Site Design", other approaches raise the question: are students provided frameworks for reading sites and or the means and methods for manipulating them? Although it can be difficult to gain a clear understanding of how and to what extent site is addressed in the courses and curricula surveyed, several suppositions may be made. First, positioning site within topics related to the natural environment has the potential to prioritize a reading of site based on natural constructors while limiting the value of the abstract and experiential. Likewise, positioning site within topics related to the urban has the potential to prioritize a reading of site based on the abstract, while limiting the value of those natural constructors that help to make up a site's physical history. Finally, not addressing site explicitly, which is the case in an overwhelming majority of schools, has the potential to establish site as other-outside the domain of architecture.

\section{SITE AS ARCHITECTURAL TECHNOLOGY}

These concerns have been born from our own experiences at Cal Poly, where until three years ago we relied on design studios to introduce students to site related topics. The immersive culture of the design studio, as well as the potential to directly apply ideas about site to a student's individual design project, related well to our University's Learn-by-Doing approach and allowed for productive experiences for many students. However, deeper reflection on our curriculum led to the recognition that our large size combined with cursory coordination between the many sections offered for each studio had resulted in an inconsistent and incomplete student attitude about site. By not addressing it explicitly, we had left site outside of the domain of architecture and in doing so had implied that site could be excluded from the authorial responsibilities of the architect. The decision was made to address site directly and explicitly within our curriculum.

As is common within schools of Architecture, we had little flexibility to add additional course units to the already impacted curriculum. In addition, we were resistant to a stand-alone course model-not wanting to isolate site from the core of architectural practice. We considered all other non-studio courses and, although initially an unlikely vehicle, we discovered opportunities in integrating site into our sequence Architectural Technology Fundamentals courses. Logistically, the technology sequence offered several benefits. First, our technology courses are the only non-studio courses taken simultaneously by all of our students, giving us a consistent platform for site issues. Second, these courses take place over multiple academic years, providing a protracted period to introduce and discuss site topics. Third, integration of site into technology encouraged us to seek productive relationships between site systems and those traditionally discussed within architectural technology, such as materials, methods of construction, and environmental control systems. Since site and contextual systems are in constant dialogue with energy, environmental, material and construction systems in the built environment, we think there is value in presenting it to students in the same interconnected way. Adding site topics to our existing understanding of technology also challenged us to rethink technology and vice versa, and to ask whether the lines between site and object and between nature and technology could find more synthetic convergence.

The integration of site has become part of a larger effort to rethink architectural technology in our curriculum. Prior to 2016, technology was taught through a series of six quarter-long courses over the 
second and third years of the five-year BArch curriculum. Four of these courses-two at each year-levelfocused on materials and methods of construction, while an additional course in each year focused on environmental control systems. Upon close examination, we observed that there were gaps in some areas of content and redundancy in others. With this in mind we sought to clarify and distinguish content by reorganizing the second-year sequence as Architectural Technology Fundamentals 1 through 3 and the third-year sequence as Architectural Systems Integration 1 through 3. Figure 1 shows the six technology courses within in the context of the suggested BArch curriculum.

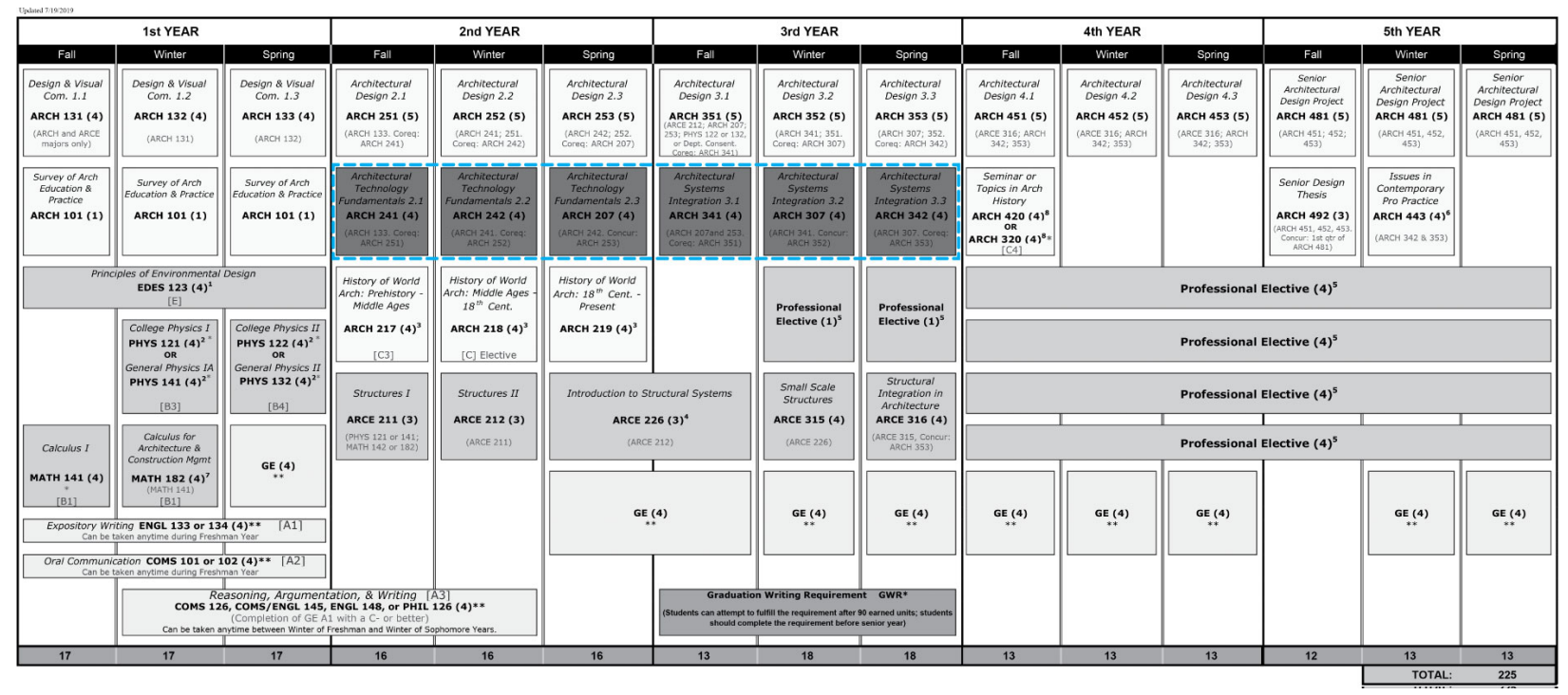

Figure 1. Bachelor of Architecture suggested 5-year academic flowchart from the 2019-20 course catalogue (Architectural Technology courses highlighted).

Whereas the tradition at Cal Poly was to expect integration of technology with design in each quarter of the sequence, the revised course names reflect our realization that younger students are often not ready to meaningfully address the technical implications of their design work. Our focus, therefore, turned toward building a stronger grasp of technology fundamentals through specially designed assignments in the second year, and shifting the complex task of integration with design to the third year. As second year technology instructors, this restructuring of our courses gave us the opportunity to rethink the relationship of fundamental technology topics to one another, challenge the notion of discrete courses for ECS and Materials and Assemblies, and, most importantly here, introduce site content into the sequence.

For the first iterations of Architectural Technology Fundamentals, the instructors of the former Environmental Control Systems and Materials and Methods courses culled content so as to create room to address site. The reorganization of the typical technology topics resulted into three study areas: Materials and Construction Systems, Energy and Environmental Systems, and Site and Contextual Systems.

Figure 2 illustrates the re-distribution of the second-year Architectural Technology curriculum to include site-related topics. 

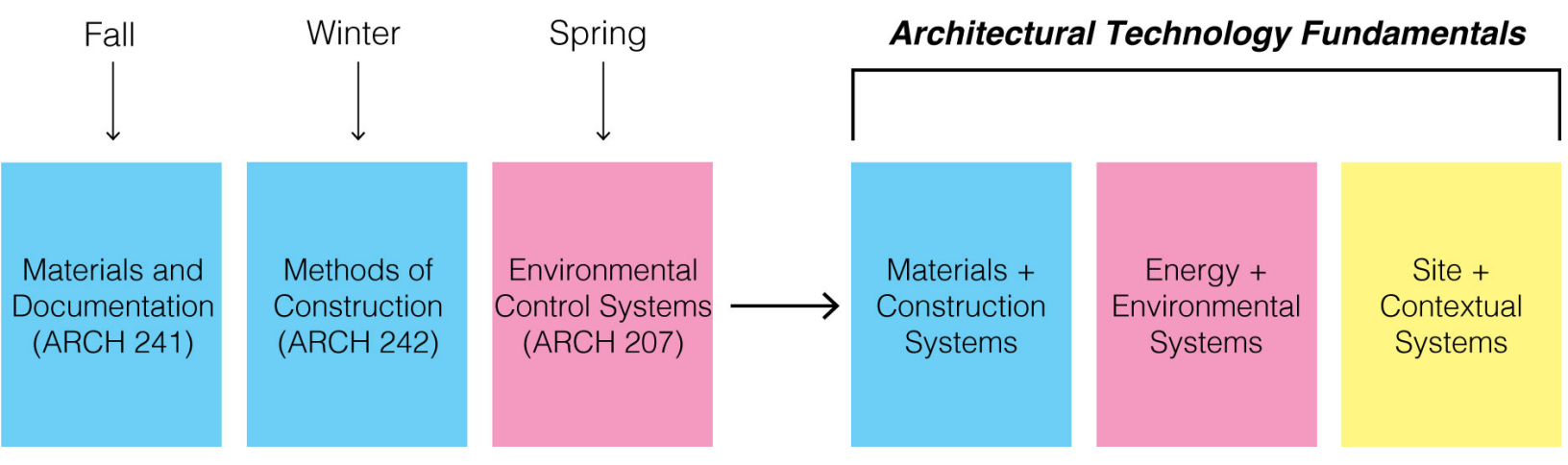

Figure 2. Re-distribution of second-year Architectural Technology curriculum to include site-related topics.

In order to allow the possibility for more productive relationships between site systems and those traditionally discussed within architectural technology, content from the three study areas was then distributed across the three quarters of the academic year in three 3-week modules each. Figure 3 diagrams the distribution of Architectural Technology Fundamentals topics across the academic year. The distributed content model allows us to tease out the complex and interrelated nature of the three study areas while also aligning our course organization with student development as well as recent shifts in contemporary practice. In the previous course structure, instruction on material properties, for instance, was offered in the fall of the second year of study. While this made material available to students as a potential driver for design inquiry early on, it also limited those discussions to the maturity of a first-term second-year student. Likewise, this schedule also resulted in the withholding of instruction on solar geometry and or principles of passive thermal control until late in the second year. Alternatively, returning to topics in shorter modules that are distributed throughout the academic year allows those discussions to deepen alongside student development. We have elaborated on these and other benefits, as well as some of the difficulties, of the distributed model in a paper titled, "The Kind of Problem Technology Is: A Case for Integrated Models of Architectural Technologies Education” in Building Technology Educator's Society: Vol. 2019.

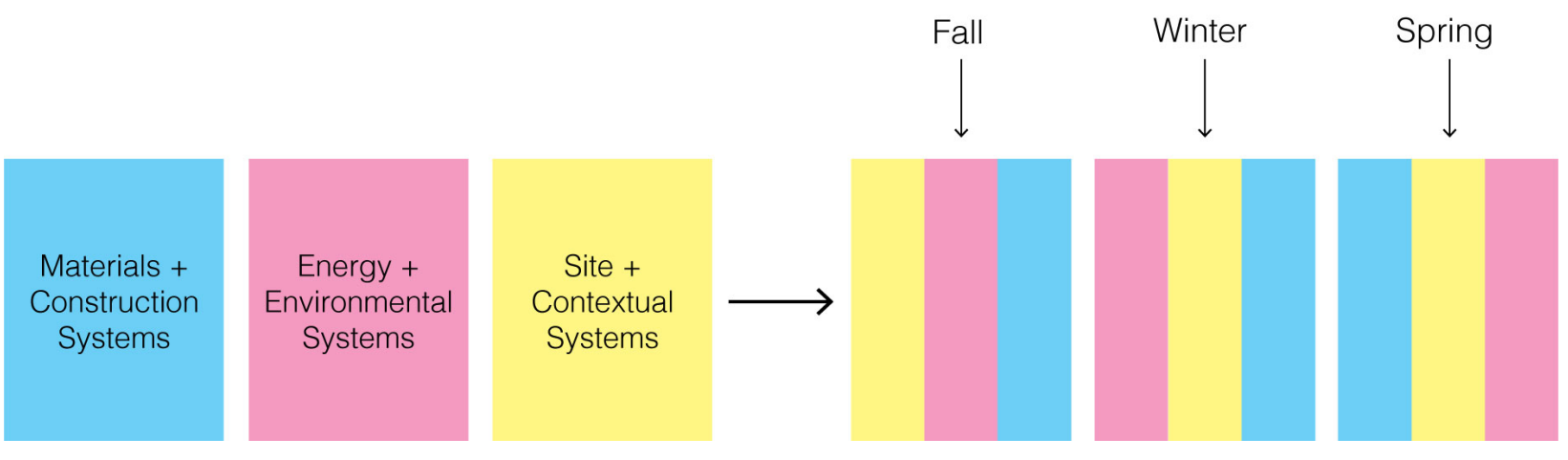

Figure 3. Distribution of second-year Architectural Technology Fundamentals topics. 


\section{Site and Contextual Systems Module Integration}

The Site and Contextual Systems topics are organized into three 3-week modules delivered in the fall, winter, and spring quarters of the second year. Each module specifically addresses a distinct situational typology, from densely bound urban contexts to more open rural sites with varied landform. The distribution of topics across the academic year enables a dialogue between the technology courses and the corequisite second-year studios, which are coordinated to address a parallel set of programs and sites throughout the year.

For instance, the fall quarter studio explores a small civic program on a local urban site. With the potential for dialogue in mind, the Site and Contextual Systems module offers frameworks for understanding architectural form as a component of the larger urban fabric. Course topics introduce methods of analyzing and responding to the abstract determinants of city form, including those regulated by local planning and zoning codes. Course discussions also introduce issues of contemporary public space and consider strategies for developing a meaningful architectural interface between a proposed building and the public realm. Figure 4 outlines the fall quarter technology topics including those from each of the three study areas.

In addition to an open dialogue with design studio, the restructuring of our courses has provided the opportunity to rethink the relationship of fundamental technology topics to one another. By positing scenarios in which multiple, and often contradictory, parameters must be negotiated, we endeavor for our students to have a more synthetic and integrative understanding of each topic area and to put those understandings to use toward thoughtful and provocative architectural proposals.

While several interactions exist within each quarter of instruction, one productive example results from the adjacency of topics in Site and Contextual Systems with those in Energy and Environmental Systems. Through a sequence of fall quarter exercises, students are asked to develop a series of building massing alternatives by interpreting the local zoning code. In a subsequent instruction module, students are introduced to solar geometry and the human benefits of natural daylight. The pairing deepens understandings of each study area by making historical ties between zoning regulations and the provision of safe and healthy conditions within dense urban settings. Further, the pairing also asks students to negotiate layered site histories including the abstract and the physical. This layering of information leads to a more nuanced study of building form in which a sensibility for the surrounding urban fabric must be negotiated with the need to shift and shear volumes in order to control solar exposure. Recalling the previous discussion of the Tarlo House provides a useful illustration in this context as well. The conflict between these two influences has great potential to inspire authorship of both site and building that overcomes these challenges while also motivating a greater understanding of the constraints. In this example, the urban fabric, the zoning codes, solar geometry, strategies for capturing natural daylight, and the ways in which these constraints can be formally addressed through building massing. We are excited that these investigations of specific site conditions have the potential to become generative in the production of architectural form.

Site + Contextual Systems

Urban Form Analysis

Planning and Zoning Codes

Public Space

Ground-floor Interface

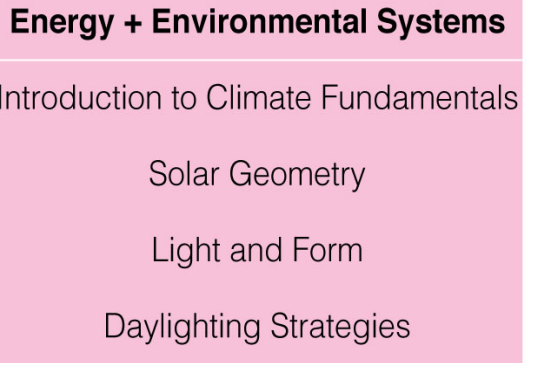

Materials + Construction Systems Building Forms and Forces

Brick + Masonry Construction

Concrete + Site Cast Construction

Figure 4. Fall-quarter module integration. 
During the winter quarter, studio interests shift toward an educational or recreational program on unbounded rural or suburban sites including sloped landforms. In response, the Site and Contextual Systems module offers introductions to soils and geology, landform and morphology, as well as hydrology. Class discussions provide a framework for initiating meaningful relationships between these natural constructors and proposed building form. Exercises introduce students to techniques of grading and drainage, especially in the context of soft surfaces, through the reading and manipulation of contours. Figure 5 outlines the technology topics from each study area that are discussed in the winter quarter.

Here a pairing of topics in Site and Contextual Systems with those in Materials and Construction Systems provides an example of how the teaching supports the notion that sites are inherently unfinished. Students are asked to consider building siting, orientation, and construction systems in exchange with landform and hydrology. As Carol Burns has described, a common preoccupation among architects, and especially beginning design students, is to assume that existing physical features, such as topography and hydrology, are inherently precious and immutable conditions of site. Instead, considering these features in dialogue with Materials and Construction Systems has the potential to establish them as parameters that must also be authored toward intended effect. As winter quarter topics turn to building foundation and roof systems, students are encouraged to see these human constructs as components of a site's hydrology, akin to the ridges and valleys that may have been formed through natural processes. This presents an opportunity for students to see constructed structures as active contributors within natural systems, rather than leaning into unproductive binaries that might otherwise separate human and natural artifacts.
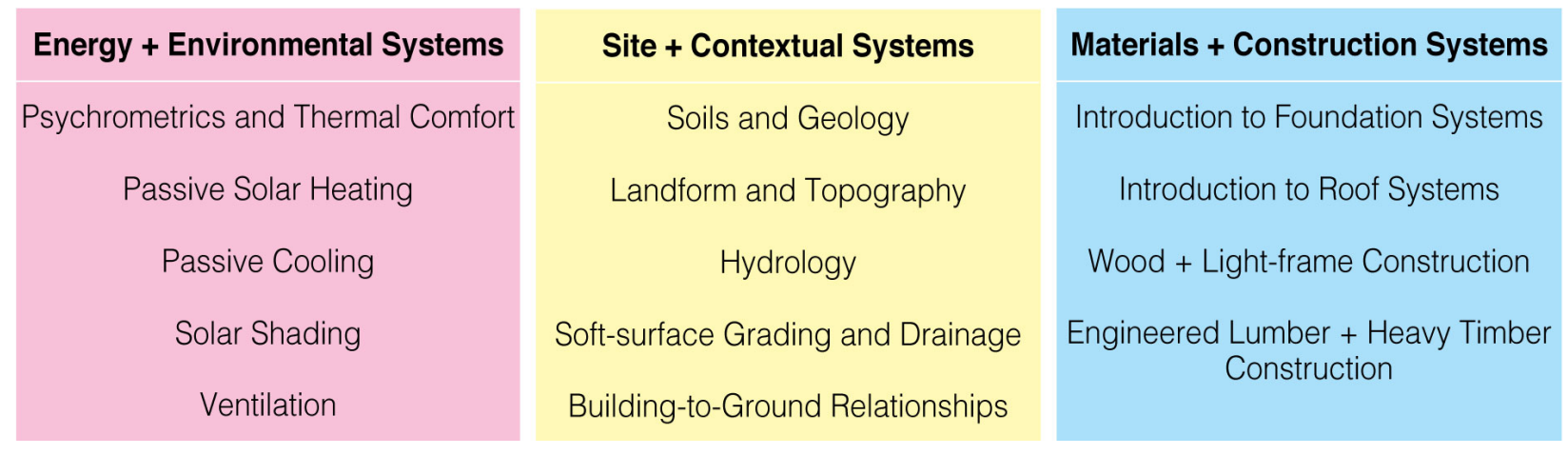

Figure 5. Winter-quarter module integration.

Finally, in the spring, the studio engages a more complex human program, often including a multi-family residential component on an urban or suburban site. The Site and Contextual Systems module presents concepts of site circulation including the integration of accessibility features into the proposed circulation strategy. Course discussions offer frameworks for considering the sequencing of user experiences throughout the site, especially related to thresholds between inside and outside. Exercises extend earlier techniques for grading and drainage; here with a focus on paved surfaces where a more finely articulated ground requires greater control through the manipulation of spot elevations. The final site module also introduces methods of constructing landscape assemblies, such as paved surfaces and grade change devices, and offers a framework for approaching planted-form in architectural contexts. Figure 6 outlines the technology topics discussed in the spring quarter including those from each of the three study areas.

The final quarter culminates with the design of a building threshold that intends to integrate, for the first time, architectural technology topics with our students' design studio projects. Through instruction and work on this exercise, site circulation and user experience are paired with issues of civil rights and life safety as well as an introduction to the science of building envelopes. Students are challenged to extend their architectural ideas from the building into the landscape, while also technically addressing legal and regulatory requirements. The exercise challenges students to design building and site circulation as a continuum of experience from moments of site arrival to program areas within the building's interior. In doing so, the design of the ground plane, including the provision of accessible routes, as well as the 
performance of landscape surface materials, or considered alongside the development of building structure and envelop assembly. As a result, students are asked to interrogate relationships between inside and outside and to make connections between the form and material of building and site features. These explorations have the potential to deepen student understanding of the properties of those materials, and how they may be used to enhance the experience of an occupant. This exercise promotes the design of site as an authorial responsibility of the architect and one that is integrally linked to questions of structure and envelope. Having this discussion within the context of architectural technology encourages students to extend their thinking beyond the limits of the building and provides them with the means and methods required to productively position site matters within the domain of architecture.

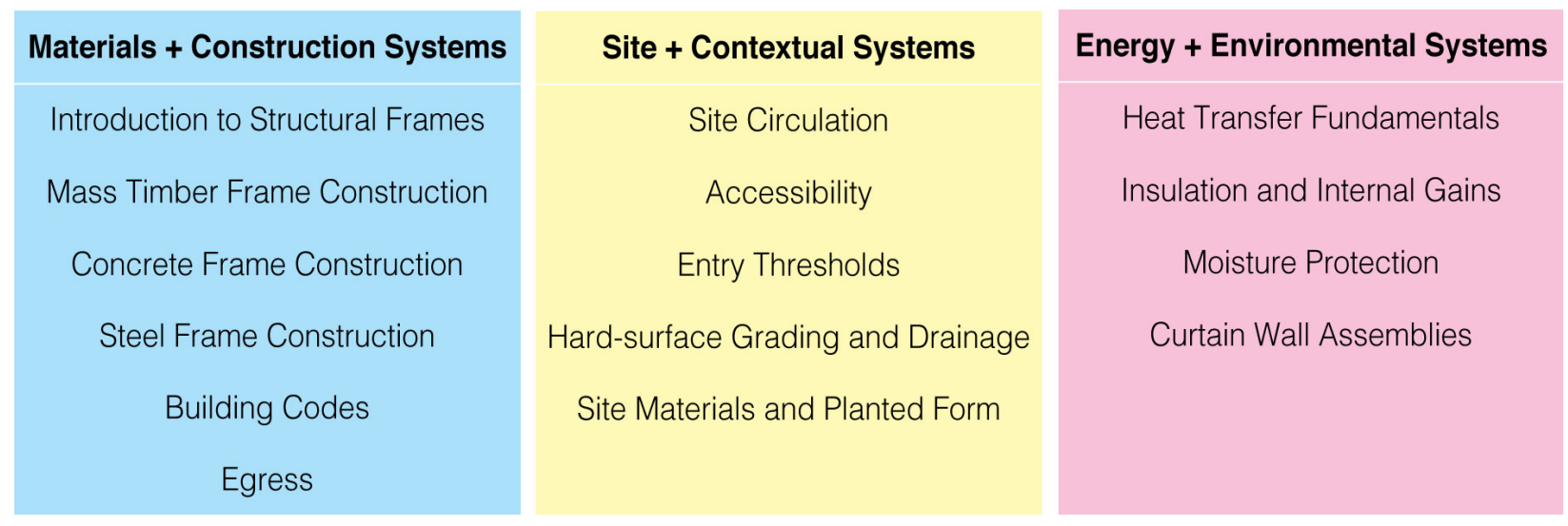

Figure 6. Spring-quarter module integration.

\section{CONCLUSION}

While our initial goals were to find ways of addressing site directly and explicitly within our curriculum, the larger potential of the pedagogy described here is to offer our students a more complete understanding of all of our architectural technology topics.

The ability to synthesize a range of diverse project constraints into thoughtful and provocative strategies for architectural design is a trait of many exceptional architects who have honed their sensibilities through experience and years of practice. Our responsibility as educators is to establish that type of synthetic and integrative thinking as a fundamental skill for second-year students. Doing so requires that we challenge the predominant tendency to isolate the topics of study that together contribute to the production of architecture.

Now entering our fourth year of course refinement, we continue to make significant alterations. While our approach to organizing course topics was initially driven by a point-of-need mentality that strove to support the design studio with the intention of integrating technology topics with design, reflection of the successes of our teaching, has led us to reconsider the value of that form or integration. Instead, this coursework may be at its best when the relationship of fundamental technology topics to one another are prioritized. Our current course developments include the tuning of these relationships and the development of course exercises that ask students to confront and negotiate them. 


\section{REFERENCES}

Arens, Robert; Osborn, Brian; and Trudell, Carmen. 2018. "The Kind of Problem Technology Is: A Case for Integrated Models of Architectural Technologies Education," Building Technology Educator's Society: Vol. 2019. Caryn Brause, Peggi L. Clouston, Naomi Darling (Eds.), Amherst, MA, 2019. Available at: https://scholarworks.umass.edu/btes/vol2019/iss1/57

Arnold, Hadley, and Michael Moran. 200o. Work/Life: Tod Williams, Billie Tsien. Monacelli Press.

Braham, William W. 2012. "Structures, Construction, Building Systems: From 'Steel as Required' to Integration .” In Architecture School Three Centuries of Educating Architects in North America, edited by Joan Ockman, 392-95. Cambridge, MA.: MIT.

Burns, Carol. 1991. "On Site: Architectural Preoccupations: Construing Common Language." In Drawing/Building/Text: Essays in Architectural Theory, edited by Andrea Kahn, 149-65. New York: Princeton Architectural Press.

Heymann, David. 2010a. “A Cloud on a Lake.” Places Journal, November 29, 2010. https://doi.org/10.22269/101129.

Heymann, David. 2010b. “Site, Ascendant.” Places Journal, December 13, 2010. https://doi.org/10.22269/101213.

Kahn, Andrea, and Carol J. Burns. 2005. "Why Site Matters." In Site Matters: Design Concepts, Histories, and Strategies. New York: Routledge.

Meyer, Elizabeth. 2005. “Site Citations: The Grounds of Modern Landscape Architecture.” Essay. In Site Matters: Design Concepts, Histories, and Strategies, edited by Andrea Kahn and Carol J. Burns, 92129. New York: Routledge.

Krauss, Rosalind. 1979."Sculpture in the Expanded Field.” October8: 30-44. https://doi.org/10.2307/778224.

"Minutes of the 47th Annual Meeting of the ACSA. 1961. " Journal of Architectural Education (19471974)16, no. 1: 3-89. https://doi.org/http://www.jstor.org/stable/1424179.

Moholy-Nagy, Sibyl. 1955. "Environment and Anonymous Architecture." Perspecta 3: 3-7+77. https://doi.org/10.2307/1566829.

Morrish, William R. 2010. Civilizing Terrains: Mountains, Mounds and Mesas. San Francisco, CA: William Stout Publishers. 